\title{
Association Between Match Activity Variables, Measures of Fatigue and Neuromuscular Performance Capacity Following Elite Competitive Soccer Matches
}

\author{
by \\ Ian Varley ${ }^{1}$, Ryan Lewin ${ }^{1}$, Robert Needham ${ }^{1}$, Robin T. Thorpe ${ }^{2}$, Ross Burbeary ${ }^{3}$
}

The aim of the study was to assess the relationships between match activity variables, subsequent fatigue and neuromuscular performance capacity in elite soccer players. Subjects $(n=10)$ were professional soccer players participating in the English Championships. Match activity variables and markers of fatigue status were measured before and following two matches. Creatine kinase (CK) and muscle soreness were measured at baseline, immediately following, as well as 40 and $64 \mathrm{~h}$ post-match. Countermovement jump performance and perceived ratings of wellness were measured at baseline, then 40 and 64 h post-match. Relationships were shown between CK and the total number of accelerations and decelerations immediately ( $r=0.63$; large), $40 \mathrm{~h}(r=0.45$; moderate) and $64 \mathrm{~h}$ post-match ( $r=0.35$; moderate) $(p<0.05)$. Relationships between CK and total sprint distance $(r=0.39$; moderate) and the number of sprints $(r=0.35$; moderate $40 \mathrm{~h}$ post-match $(p<0.05)$ were observed. Furthermore, relationships were shown between the perceived rating of wellness and number of accelerations $40(r=0.52$; large $)$ and $64 \mathrm{~h}(r=0.40$; moderate $)$ post-match, sprint distance $40 \mathrm{~h}$ post-match $(r=0.40 ;$ moderate) and the total number of sprints $40 \mathrm{~h}$ post-match $(r=0.51 ;$ large $)(p$ $<0.05)$. The quantification of match activity variables, particularly the total number of accelerations and decelerations and the number of sprints, provides insights into the fatigue status in elite soccer players 40 and $64 \mathrm{~h}$ post-match.

Key words: recovery, acceleration, deceleration, creatine kinase, exercise.

\section{Introduction}

Elite soccer players are required to participate in a high number of competitive matches (40-50) which are, in some cases, separated by as little as 48-72 h. Due to the frequency of matches, a large amount of strain is placed on a number of physiological systems (Stølen et al., 2005). General fatigue (Ascensão et al., 2008) and a reduction in strength (Oliver et al., 2008) have been shown following competitive soccer matches. Furthermore, soccer matches are also known to elicit exercise induced muscle damage and subsequent soreness, which is thought to be due to the high magnitude eccentric muscle loading derived from training and matches (Mohr et al., 2016). It has been shown that various potential fatigue measures do not return to baseline levels up to $72 \mathrm{~h}$ following a match (Ascensão et al., 2008). This has led to various recovery strategies being implemented in attempt to hasten player recovery and thus regain optimum performance and reduce susceptibility to fatigue related injuries (Nédélec et al., 2013). Although challenging due to the multi-factorial nature of fatigue (Thorpe et al., 2015), tools that enable the effective identification and quantification of fatigue are useful in the prescription of post-match training and injury prevention strategies.

\footnotetext{
1 - Sport, Health and Performance Enhancement Research Centre, Nottingham Trent University, Clifton Lane, Nottingham, UK.

2 - Football Medicine and Science Department, Manchester United Football Club, UK.

3 - Nottingham Forest Football Club, The City Ground Nottingham, UK.
} 
Although multiple biochemical and physiological markers of post-match play fatigue exist, Creatine Kinase (CK) is the most widely used marker of fatigue status in an applied setting (Ascensão et al., 2008; Russell et al., 2015). It has been demonstrated that levels of serum CK are elevated following intensive exercise (Ascensão et al., 2008; Garry and McShane, 2000), and the presence of $\mathrm{CK}$, in healthy participants, is correlated with sarcomeric damage (Brancaccio et al., 2000). Ascensão et al. (2008) showed levels of CK to be significantly elevated in Portuguese 2nd tier soccer players 48 and $72 \mathrm{~h}$ post-match alongside, which resulted in significantly reduced lower limb strength and sprint ability. Similarly, CK increased 24 and $48 \mathrm{~h}$ following a competitive reserve soccer match compared to baseline measures (Russell et al., 2015). The reason for this is thought to be due to soccer specific activity, such as rapid accelerations and decelerations leading to a large amount of eccentric loading which is synonymous with muscle architecture disruption (Brown et al., 1999; Proske and Morgan, 2001). Previous research (Ascensão et al., 2008; Russell et al., 2015) has relied solely on CK as an individual marker of fatigue, however, fatigue has been shown to be multi-factorial (Thorpe et al., 2015). Measurements of neuromuscular capacity, such as a countermovement jump, have previously been reported to be able to detect fatigue status in team sports players following match-play (Johnston et al., 2013). Therefore, it can be suggested that multiple factors need to be considered when assessing fatigue status given the lack of evidence related to the use of single measures of fatigue status in an applied, competitive, elite scenario (Meister et al., 2013).

Despite the importance of monitoring recovery and the individual variability in the extent of fatigue experienced following matches (Ascensão et al., 2008; Thorpe et al., 2015), measures of muscle damage are not commonly assessed. If associations could be made between routinely assessed match activity variables (FIFA permitting the use of GPS decives in competitive matches may increase the regularity in which match activity variables are measured) and fatigue measures, this would provide sport scientists within clubs with greater insight into individual fatigue status. Therefore, the aim of the present study was to determine the association between commonly recorded match activity variables during elite competitive matches and measures of fatigue and neuromuscular performance capacity immediately, 40 and $64 \mathrm{~h}$ post-match.

\section{Methods}

In order to provide a representative cohort of elite soccer players, data were collected from two competitive matches separated by 21 days played in September 2014. Match activity variables and subsequent measures of fatigue and neuromuscular performance capacity were collected during and following two English Championship matches. Baseline measures of fatigue and neuromuscular performance capacity were assessed following three days of rest (no training or matches) $\sim 3$ weeks prior to the experimental period.

\section{Participants}

Sixteen male elite soccer players $(27.4 \pm$ 3.1 years; $180 \pm 5 \mathrm{~cm} ; 82.4 \pm 6.8 \mathrm{~kg}$ ) from a club competing in the English Championships volunteered to participate in the study. Players that completed $>60 \mathrm{~min}$ of the match were included in the analysis. Of the players analysed, one player did not complete 90 min during the match (match time $>60 \mathrm{~min}$ ). Six players were removed from the analysis due to injury or lack of availability for follow-up measurements ( $\mathrm{n}=10$ for analysis). All players were made aware of experimental procedures and provided informed consent prior to taking part in the experiment. The study was ethically approved by the Nottingham Trent University ethics committee.

\section{Measures}

Sprint distance, total distance, the number of accelerations and decelerations and the number of sprints (Di Salvo et al., 2006) were assessed using Prozone Matchviewer (Prozone ${ }^{\circledR}$ Sports Ltd, Leeds, United Kingdom). Prozone Matchviewer had been previously shown to be a valid and reliable (Bradley et al., 2007; Di Salvo et al., 2006) measure of performance characteristics. A sprint was considered when a player reached a speed in access of $7 \mathrm{~m} \cdot \mathrm{s}^{-1}$, accelerations and decelerations were categorised as a change in speed $>4 \mathrm{~m} \cdot \mathrm{s}^{-1}$ in accordance with standardised Prozone metrics.

All measures of fatigue were assessed at 
baseline, immediately (with the exception of perceived ratings of wellness and CMJ), 40 and 64 $\mathrm{h}$ following a match.

\section{Procedures}

Creatine kinase $(\mathrm{CK})$ - capillary blood samples were collected in order to measure serum CK. Samples were collected at the clubs training facility or stadium on arrival (Baseline, 40 and 64 $\mathrm{h}$ post-match) and immediately following a match (post-match), and stored on ice before subsequent analysis. Samples were analysed using the ABX Pentra 400 (Horiba medical, Kyoto, Japan) in accordance with manufacturer's instructions. Samples were analysed in duplicate with the coefficient of variation shown to be $3.2 \%$

Visual Analogue Scale of Muscle Fatigue (VASMF) - muscle soreness was measured on a visual analogue scale (Seymour et al., 1985). Participants were asked to apply a mark to a 20 $\mathrm{cm}$ line that indicated no muscle soreness, 'legs don't feel tired at all' at one extreme and severe muscle soreness, 'legs feel so tired it hurts to move them' at the other extreme. The line was then measured with a ruler and scores were converted into a percentage.

Perceived ratings of wellness - perceived ratings of wellness were obtained by using a series of questions adapted from Hooper et al. (1995). Questions were scored on a numerical scale: 1). How energetic do you feel? $(1=$ struggling, $5=$ full of beans) 2 ). How do your legs feel? $(1=$ sore, $5=$ strong $) 3)$. How much sleep did you get last night? $(1=0-3 h, 5=9+h) 4)$. Overall, physically how good do you feel today? $(1=$ Awful, $10=100 \%$ ). Scores were added together to give an overall wellness index.

Countermovement jump (CMJ) - the CMJ was used as a reliable (Ortega et al., 2008) and valid (Bosco et al., 1983) indicator of the neuromuscular system performance (CV 2.2\%). CMJ performance (height) was assessed by participants standing in an upright position with their hands on the hips, squatting to their preferred depth, and concentrically contracting to jump as high as possible while standing on a jump mat (Optojump next, Mircogate, Bolzano, Italy). Participants performed three jumps following two practice jumps. The highest jump was recorded for further analysis.

\section{Statistical Analysis}

Data were tested for normality using the
Shapiro-Wilk test. A one-way ANOVA was performed in order to analyse the data collected for CK activity and CMJ performance. VASMF scores and perceived ratings of wellness were analysed using the Kruskal-Wallis test. The Pearson product-moment correlation coefficient was used to evaluate the strength of the linear relationship between individual measures of fatigue, neuromuscular performance capacity and match activity variables. The magnitude of the correlation between match activity variables measured, measures of fatigue and neuromuscular performance capacity were classified according: $<0.1$ trivial, 0.1 to 0.3 small, 0.3 to 0.5 moderate, 0.5 to 0.7 large, 0.7 to 0.9 very large, and 0.9 to 1.0 almost perfect (Hopkins, 2000). Confidence intervals (95\%) and effect sizes were also calculated. Statistical analyses were performed using the statistical package for social sciences version 23.0 (SPSS, Inc., Chicago, IL, USA). Acceptable level of significance was set at $p$ $<0.05$.

\section{Results}

Serum CK activity (Figure 1) was significantly higher post-match and $40 \mathrm{~h}$ postmatch when compared to baseline (post-match CI $426-966$, effect-size $=1.46, p=0.03 ; 40 \mathrm{~h}-\mathrm{CI}$ $400-1148$, effect-size $=1.11, p=0.01)$. No differences were observed when $64 \mathrm{~h}$ post-match values were compared to baseline (CI $324-882$, effect-size $=1.03, p=0.15$ )

VASMF scores were significantly higher post-match (CI $39.4-73.6$, effect-size $=1.46, p=$ $0.000), 40 \mathrm{~h}$ post-match $(\mathrm{CI} 10.4-43.2$, effect-size $=$ $0.73, p=0.001$ ) and $64 \mathrm{~h}$ post-match (CI $21.8-39.8$, effect-size $=0.55, p=0.004$ ) compared to baseline measurements. CMJ performance and perceived ratings of wellness were not significantly different at any time points compared to baseline (CMJ 40 h, CI 48.2 - 55.5, effect-size $=0.17, p=0.46$; CMJ 64 h, CI 49.3 - 57.1, effect-size $=0.03, p=0.57$; Wellness 40 h, CI 16-18, effect-size $=0.5, p=0.12$; Wellness $64 \mathrm{~h}, \mathrm{CI} 17-19$, effect-size $=0.00, p=$ 0.81).

CK activity was correlated with the total number of accelerations and decelerations at alltime points (post-match - CI $-0.24-1.25, \mathrm{p}=0.010$, large; $40 \mathrm{~h}$ - CI -0.38-1.28, $p=0.034$, moderate; $64 \mathrm{~h}$ - CI -0.37 - 1.66, $p=0.046$, moderate) (Table 1). CK activity was also correlated with the number of 
sprints (CI $0.00-1.07, p=0.047$, moderate) and total sprint distance $40 \mathrm{~h}$ post-match (CI 0.01 1.07, $p=0.048$, moderate). VASMF scores were correlated with total distance covered immediately post-match (CI $-0.08-1.03, p=0.038$, moderate), although no significant or substantial correlation was found in relation to other performance variables at any time point (Table 1, all $p>0.05)$. Perceived ratings of wellness were correlated with the number of accelerations $(40 \mathrm{~h}$ post-match- CI $-0.29-1.07, p=0.024$, large; $64 \mathrm{~h}$ post-match- $\mathrm{CI} 0.40-0.86, p=0.041$, large) and the number of sprints $(40 \mathrm{~h}$ post-match - CI $-0.20-$ $0.96, p=0.047$, large). CMJ performance did not significantly correlate with any match activity variables (all $p>0.05$ ).

\section{Table 1}

Correlations between measures of fatigue and performance variables measured during a match $(C K=$ Creatine Kinase; $V A S M F=$ Visual Analogue Scale of Muscle Fatigue; Wellness = Perceived ratings of wellness;

$C M J=$ Countermovement Jump; $P M=$ Post-Match).

\begin{tabular}{|c|c|c|c|c|c|c|c|c|c|c|}
\hline \multirow[b]{2}{*}{ Variable } & \multicolumn{3}{|c|}{ CK } & \multicolumn{3}{|c|}{ VASMF } & \multicolumn{2}{|c|}{ Wellness } & \multicolumn{2}{|c|}{ CMJ } \\
\hline & PM & $\begin{array}{l}+40 \\
\mathrm{~h}\end{array}$ & $\begin{array}{l}+64 \\
\mathrm{~h}\end{array}$ & PM & $\begin{array}{l}+40 \\
\mathrm{~h}\end{array}$ & $\begin{array}{l}+64 \\
\mathrm{~h}\end{array}$ & $+40 \mathrm{~h}$ & $+64 \mathrm{~h}$ & $+40 \mathrm{~h}$ & $+64 \mathrm{~h}$ \\
\hline $\begin{array}{l}\text { Sprint } \\
\text { distance }\end{array}$ & 0.35 & $0.39^{*}$ & 0.30 & 0.34 & 0.18 & -0.13 & $0.40^{*}$ & -0.02 & 0.27 & 0.15 \\
\hline Total distance & 0.20 & 0.11 & -0.02 & $0.36^{*}$ & -0.02 & -0.25 & 0.21 & 0.02 & 0.04 & -0.06 \\
\hline Accelerations & -0.05 & 0.07 & 0.01 & 0.23 & -0.14 & 0.29 & $0.52^{*}$ & $0.40^{*}$ & 0.27 & 0.09 \\
\hline Decelerations & 0.09 & 0.01 & 0.00 & 0.06 & 0.14 & 0.10 & 0.32 & 0.03 & 0.15 & 0.16 \\
\hline $\begin{array}{l}\text { Total accel } \\
\text { and decel }\end{array}$ & $0.63^{*}$ & $0.45^{*}$ & $0.35^{*}$ & 0.27 & 0.20 & 0.16 & 0.22 & -0.07 & 0.29 & 0.20 \\
\hline $\begin{array}{l}\text { Number of } \\
\text { sprints }\end{array}$ & 0.28 & $0.35^{*}$ & 0.26 & 0.34 & 0.02 & 0.28 & $0.51^{*}$ & 0.12 & 0.21 & 0.17 \\
\hline
\end{tabular}

$\left({ }^{*}=\right.$ significant correlation; $\left.p<0.05\right)$

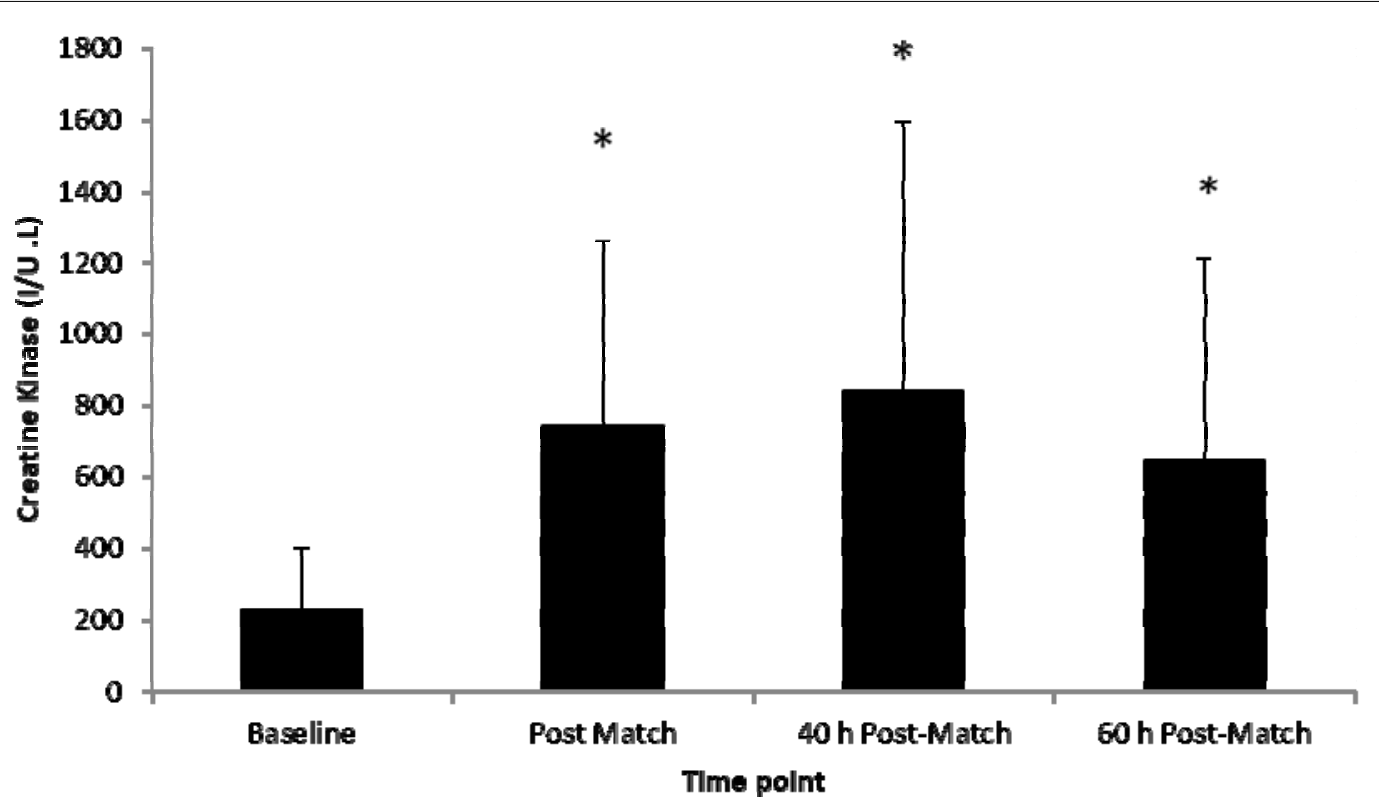

Figure 1

Creatine Kinase activity. Values reported as Mean $\pm S D(B L=$ Baseline $)$.

* denotes a $p<0.05$ when compared to baseline. 


\section{Discussion}

The aim of the present study was to assess the relationships between match activity variables commonly measured during soccer matches and subsequent potential measures of fatigue and neuromuscular performance capacity. The total number of accelerations and decelerations and the number of sprints performed demonstrated the strongest associations with CK activity, perceived ratings of muscle soreness and perceived ratings of wellness. The large between match variability in match activity variables seen in elite soccer can cause a high degree of individuality in fatigue and neuromuscular performance capacity experienced by elite soccer players (Bangsbo et al., 2006; Gregson et al., 2010; Mohr et al., 2013). The moderate and large relationships shown between individual match activity variables and measures of fatigue status show that match activity variables can be used as an effective, efficient and non-invasive measure of individual player fatigue, which can inform individual recovery and training prescription.

Effective and efficient assessment of player fatigue and neuromuscular performance capacity in elite soccer is of paramount importance due to the frequency of competition and the short period of time (48-72 h) between matches. Effective fatigue and neuromuscular performance capacity monitoring can provide insights into player physiological status, which may then further help in the attempt to reduce the susceptibility of injury and illness in elite soccer players. As expected, serum CK activity remained significantly elevated at all-time points compared to baseline measurements which is in line with previous findings (Ascensão et al., 2008; Russell et al., 2015). The association of CK activity with total sprint distance, the number of sprints and total number of accelerations and decelerations supports associations shown in Australian rules football (Young et al., 2012) and the hypothesis that the high intensity components of a soccer match cause muscular damage (Meister et al., 2013). Accelerations and decelerations are characterised by a rapid switch between concentric and eccentric contractions, and sprinting necessitates large magnitude of the mechanical load, both of which contribute to the mechanisms of muscle damage (Proske and Morgan, 2001). Data collected following a Rugby
Union match have also shown the number of sprints, sprint distance and high-speed sprinting distance to be moderately correlated with CK activity, albeit only in players of certain positions (backs) (Jones et al., 2014). As CK activity is rarely assessed in competitive elite sport, probably due to the invasive procedures involved, the correlations shown with commonly measured match activity variables provide an alternative to an otherwise unattainable measurement of fatigue status up to $64 \mathrm{~h}$ post-match.

Perceived ratings of muscle soreness measured directly following a match showed a moderate relationship with total distance covered, however, no associations were shown 40 and $64 \mathrm{~h}$ post-match. These findings seem to be in line with data from other sports showing perceived fatigue to be increased $24 \mathrm{~h}$ following a match (Twist et al., 2012). Although data collected $24 \mathrm{~h}$ following a match are of interest and indicate the level of fatigue experienced, as professional soccer players are rarely asked to perform high intensity activity $24 \mathrm{~h}$ post-match, the findings could be deemed of limited applied importance. The large relationship shown between perceived ratings of wellness and the number of sprints (large, $40 \mathrm{~h}$ post-match) and accelerations (large, $40 \mathrm{~h}$ and moderate $64 \mathrm{~h}$ postmatch) is in line with data from Australian Rules Football showing correlations between training loads and perceived quality of sleep (Buchheit et al., 2013). However, no associations were shown between a daily training load and the same variables in a different cohort of elite soccer players (Thorpe et al., 2015). The perceived nature of the assessment and the lack of control over extenuating factors such as peer-influence, not linked to training/match, may have influenced 'wellness' and could be the reason for the contrasting findings (Saw et al., 2015).

Despite a reduction in neuromuscular performance capacity being commonly associated with muscular fatigue (Proske and Morgan, 2001) and a decrease in CMJ performance (jump height) previously being shown following soccer participation (Kotzamanidis et al., 2005; Oliver et al., 2008), no changes in CMJ height were shown following a soccer match in the present study. However, the data shown are in line with findings in elite players showing CMJ performance to remain unchanged following daily training loads and matches (Thorpe et al., 2015). It could be 
suggested that players subtly vary $\mathrm{CMJ}$ technique in a fatigued state and maintain jump height through compensatory mechanisms, such as greater eccentric depth before jumping, increased inertia due to the strength shortening cycle through faster arm drive and 'catching' a deeper bent knee landing to increase flight time. Analysis of jump height may also not be sensitive to the acute effects of a match and therefore, analysis of alternative measures during the $\mathrm{CMJ}$, such as concentric force and eccentric duration may be beneficial in future applied studies (Quagliarella et al., 2011).

The present study benefits from using a cohort of elite soccer players taking part in competitive matches, however, the applied nature of the study reduces the amount of control that can be achieved. Players diet and rest day activity were not standardised, however, as all the subjects were professional soccer players, it is unlikely that substantial differences in dietary intake or rest day activity occurred, therefore we believe these factors are unlikely to have influenced the current findings.

In conclusion, the correlations between match activity variables and fatigue status show that the quantification of individual match activity variables, particularly the total number of accelerations and decelerations and the number of sprints, provides a useful non-invasive indicator of subsequent fatigue status in elite soccer players in the days following a match.

\section{Acknowledgements}

The authors have no conflict of interests and no external funding was provided. The authors would like to thank all the participants that volunteered to take part.

\section{References}

Ascensão A, Rebelo A, Oliveira E, Marques F, Pereira L, Magalhães J. Biochemical impact of a soccer match-analysis of oxidative stress and muscle damage markers throughout recovery. Clin Biochem, 2008; 41: 841-851. doi: 10.1016/j.clinbiochem.2008.04.008

Bangsbo J, Mohr M, Krustrup P. Physical and metabolic demands of training and match-play in the elite football player. J Sports Sci, 2006; 24: 665-74

Bosco C, Luhtanen P, Komi PV. A simple method for measurement of mechanical power in jumping. Eur J Appl Physiol Occup Physiol, 1983; 50: 273-282

Bradley PS, O'Donoghue PG, Wooster B, Tordoff P. The reliability of ProZone MatchViewer: A video-based technical performance analysis system. Int J Perform Anal Sport, 2007; 7: 117-129

Brancaccio P, Maffulli N, Limongelli FM. Creatine kinase monitoring in sport medicine. Br Med Bull, 2007; 81: 209-230

Brown S, Day S, Donnelly A. Indirect evidence of human skeletal muscle damage and collagen breakdown after eccentric muscle actions. J Sports Sci, 1999; 17: 397-402

Buchheit M, Racinais S, Bilsborough JC, Bourdon PC, Voss SC, Hocking, J et al. Monitoring fitness, fatigue and running performance during a pre-season training camp in elite football players. J Sci Med Sport, 2013; 16: 550-555. doi: 10.1016/j.jsams.2012.12.003

Di Salvo V, Collins A, McNeill B, Cardinale M. Validation of ProZone: a new video-based performance analysis system. Int J Perform Anal Sport, 2006; 6: 108-119

Garry JP, McShane JM. Post competition elevation of muscle enzyme levels in professional football players. MedGenMed, 2000; 2: E4-E4

Gregson W, Drust B, Atkinson G, Salvo VD. Match-to-match variability of high-speed activities in premier league soccer. Int J Sports Med, 2010; 31: 237-242. doi: 10.1055/s-0030-1247546

Hooper SL, Mackinnon LT, Howard A, Gordon RD, Bachmann AW. Markers for monitoring overtraining and recovery. Med Sci Sports Exerc, 1995; 27: 106-112

Hopkins WG. Measures of reliability in sports medicine and science. Sports Med, 2000; 30: 1-15

Johnston RD, Gibson NV, Twist C, Gabbett TJ, MacNay SA, MacFarlane NG. Physiological responses to an intensified period of rugby league competition. J Strength Cond Res, 2013; 27: 643-654. doi: 10.1519/JSC.0b013e31825bb469 
Jones MR, West DJ, Harrington BJ, Cook CJ, Bracken RM, Shearer DA, Kilduff LP. Match play performance characteristics that predict post-match creatine kinase responses in professional rugby union players. BMC Sports Sci Med Rehabil, 2014; 3: 38. doi: 10.1186/2052-1847-6-38

Kotzamanidis C, Chatzopoulos D, Michailidis C, Papaiakovou G, Patikas D. The effect of a combined highintensity strength and speed training program on the running and jumping ability of soccer players. $J$ Strength Cond Res, 2005; 19: 369-375

Meister S, Faude O, Ammann T, Schnittker R, Meyer T. Indicators for high physical strain and overload in elite football players. Scand J Med Sci Sports, 2013; 23: 156-163. doi: 10.1111/j.1600-0838.2011.01354.x

Mohr M, Krustrup P, Bangsbo J. Match performance of high-standard soccer players with special reference to development of fatigue. J Sports Sci, 2013; 21: 519-528

Mohr M, Draganidis D, Chatzinikolaou A, Barbero-Álvarez JC, Castagna C, Douroudos I, Avloniti A, Margeli A, Papassotiriou I, Flouris AD, Jamurtas AZ, Krustrup P, Fatouros IG. Muscle damage, inflammatory, immune and performance responses to three football games in 1 week in competitive male players. Eur J Appl Physiol, 2015; 116: 179-93. doi: 10.1007/s00421-015-3245-2.

Nédélec M, McCall A, Carling C, Legall F, Berthoin S, Dupont G. Recovery in Soccer: : part ii-recovery strategies. Sports Med, 2012; 43: 9-22. doi: 10.1007/s40279-012-0002-0

Oliver J, Armstrong N, Williams C. Changes in jump performance and muscle activity following soccerspecific exercise. J Sports Sci, 2008; 26: 141-148

Ortega FB, Artero EG, Ruiz JR, Vicente-Rodriguez G, Bergman P, Hagströmer M, Reliability of health-related physical fitness tests in European adolescents. The HELENA Study. Int J Obes (Lond), 2008; 32: S49-57. doi: $10.1038 /$ ijo.2008.183

Proske U, Morgan DL. Muscle damage from eccentric exercise, mechanism, mechanical signs, adaptation and clinical applications. J Physiol, 2001; 537: 333-345

Quagliarella L, Sasanelli N, Belgiovine G, Accettura D, Notarnicola A, Moretti B. Evaluation of counter movement jump parameters in young male soccer players. J Appl Biomater Biomech, 2011; 9: 40-46. doi: 10.5301/JABB.2011.7732

Russell M, Northeast J, Atkinson G, Shearer DA, Sparkes W, Cook CJ, Kilduff LP. The between-match variability of peak power output and Creatine Kinase responses to soccer match-play.J Strength Cond Res, 2015; 29: 2079-2085. doi: 10.1519/JSC.0000000000000852

Saw AE, Main L, Gastin PB. Monitoring athletes through self-report: Factors influencing implementation. J Sports Sci Med, 2015; 14: 137-146

Seymour RA, Simpson JM, Charlton JE, Phillips ME. An evaluation of length and end-phrase of visual analogue scales in dental pain. Pain, 1985; 21: 177-185

Stølen T, Chamari K, Castagna C, Wisløff U. Physiology of soccer. Sports Med, 2005; 35: 501-536

Thorpe RT, Strudwick AJ, Buchheit M, Atkinson G, Drust B, Gregson W. Monitoring Fatigue During the InSeason Competitive Phase in Elite Soccer Players. Int J Sports Physiol Perform, 2015; 10: 958-64. doi: 10.1123/ijspp.2015-0004

Twist C, Waldron M, Highton J, Burt D, Daniels M. Neuromuscular, biochemical and perceptual post-match fatigue in professional rugby league forwards and backs. J Sports Sci, 2012; 30: 359-367. doi: 10.1080/02640414.2011.640707

Young WB, Hepner J, Robbins DW. Movement demands in Australian rules football as indicators of muscle damage. J Strength Cond Res, 2012; 26: 492-496. doi: 10.1519/JSC.0b013e318225a1c4

\section{Corresponding author:}

\section{Dr. Ian Varley}

Musculoskeletal Physiology Research Group

Sport, Health and Performance Enhancement Research Centre

School of Science and Technology; Nottingham Trent University, NG11 8NS, UK.

Phone: +44 (0) 1158483452

E-mail: Ian.Varley@ntu.ac.uk 